Knowledge transfer within relationship portfolios: the creation of knowledge recombination rents

\title{
Knowledge Transfer within relationship portfolios: The Creation of Knowledge
}

\section{Recombination Rents}

Peer reviewed version forthcoming in Business Process Management Journal

DOI: 10.1108/BPMJ-06-2017-0171

Massimiliano M. Pellegrini, University of Rome Tor Vergata, Italy

Andrea Caputo, University of Lincoln, United Kingdom

Lee Matthews, University of Lincoln, United Kingdom

\section{Abstract}

Purpose: The purpose of this article is to clarify the underdeveloped conceptualization of a particular type network rents, defined as knowledge recombination rents, related to the possibility for a firm to transfer and recombine knowledge within and across its portfolio of inter-organizational relationships. Design/methodology/approach: Adopting a contingency approach, we develop a comprehensive model with propositions drawn from an original synthesis of the extant literature on the management of inter-organizational relationships.

Findings: We summarize the most important internal and external variables that explain how knowledge recombination rents arise within a firm's portfolio of inter-organizational relationships. We create a seven-proposition model that considers: an "internal fit", related to internal contingencies of the firm, specifically life stage and its strategy; an "external fit", related to external contingencies of the network of the firm, specifically past experience and current portfolio structure.

Research limitations/implications: The model is theory-driven. Future research is needed to empirically validate the propositions, especially in different industries and contexts.

Practical implications: Our model, beyond the fact of being theoretically sounded, is also completely practical oriented. Indeed, we developed a comprehensive model articulated in seven propositions which relationship managers can easily use to analyze and manage their portfolios of interorganizational relationships.

Originality/value: Our model allows us to assert that the value of an inter-organizational relationship is not fixed nor just related to the single dyadic interaction; rather before engaging with a relationship is crucial to ponder possible benefits and harms. This is the central element in our contribution that develops an easy-to-use and comprehensive model based on best practices.

Keywords: Knowledge Recominbination Rents, Knowledge Transfers and Spillovers, Recombination Processes, Inter-organizational Relationships, Relationship Management, Alliance and Network Portfolio, Exploration/Exploration 
Knowledge transfer within relationship portfolios: the creation of knowledge recombination rents

\section{Introduction}

In recent years, the strategic management of knowledge has increasingly turned its

attention to the relational rents that can be created through inter-organizational relationships, partnerships, and alliances (Dyer \& Singh, 1998). An impressive body of literature has emerged in order to understand how organizations can create relational rents through the transfer of knowledge within individual inter-organizational relationships. However, it is less clear how knowledge is transferred across the relationships within a company's portfolio of relationships. This represents a significant gap within the literature as the ability to transfer knowledge across a portfolio of relationships is vitally important for organizations as it allows them to understand what is the potential for recombining the different knowledges

concept of dyadic rent is useful for understanding knowledge transfer within individual interorganizational relationships, it has a number of limitations as a tool for understanding how knowledge is transferred across relationships within a portfolio to create knowledge occur simultaneously and reciprocal influences especially for the most innovative organizations (Powell, Koput, \& Smith-Doerr, 1996). Second, the portfolio space in which such relationships are managed is not merely a frame for these business processes but rather a factor influencing the structure and evolution of relationships (Gulati, 1998). In recognition of these facts, inter-organizational studies have expanded the focus from the dyadic level to 
Knowledge transfer within relationship portfolios: the creation of knowledge recombination rents

the network level of a firm (Yang, Lin, \& Lin, 2010). This network approach facilitates a better understanding of how organization manage their entire portfolio of relationships alliances (Zhao, 2014) and manage these business processes more holistically to produce knowledge recombination rents. Despite the extensive debate on the topic (e.g. Lavie, 2006; Rothaermel \& Deeds, 2004; Sidhu, Commandeur \& Volberda, 2007), the extant literature is still lacking a clear and analytic representation of the rents that arise from the recombination of firms' knowledge within a portfolio of relationships and this is exactly the gap that we aim to fill in this paper with our novel concept of 'knowledge recombination rents'.

Thus, this paper, is positioned within the broader field of studies investigating the impact of managing knowledge on partnership strategies, and aims at answering the following research question: What conditions and factors increase knowledge recombination rents within a company's portfolio of relationships? We developed a model made of seven propositions on the nature and development of these knowledge recombination rents. Consistent with the extant literature (e.g., Ronald S Burt, 2000; Jiang, Tao, \& Santoro, 2010; Koka \& Prescott, 2008; Pett \& Clay Dibrell, 2001; Zhao, 2014), we adopt a contingency approach (e.g., Pratono, 2016; Zaheer \& Bell, 2005) in order to focus on the internal and external conditions of fit (Zajac, Kraatz, \& Bresser, 2000) that determine how firms are able to create potential knowledge recombination rents through their portfolio of inter-organizational relationships.

We are determining what is the potential value of such knowledge transfer as in purely RV approach, which indeed interprets relational value as a combination of resources and capability strategically developed and deployed (Dyer \& Singh, 1998), rather than the dynamic capabilities approach (Zollo \& Winter, 2002), which is more interested in studying processes and routines apt to catch such relational value (Lorenzoni \& Lipparini, 1999). 
Knowledge transfer within relationship portfolios: the creation of knowledge recombination rents

The contribution of our work to the literature is twofold. The first contribution is

theoretical. We present a holistic framework that is able to show how a company can recombine knowledge within its portfolio of relationships and thus deepens our understanding of the most important aspects that should be considered ex-ante before starting. The second contribution is practical. The framework can be used by organizations as an "easy to use" tool based on seven points that managers can use in the strategic planning process for their portfolios of inter-organizational relationships.

The paper is structured as follows: a problem statement made in this introduction, our model of knowledge recombination rents is presented in the 'Model Development' section; next seven propositions present the contingencies that will determine the possibilities for knowledge recombination rents within a portfolio of relationships; next, we discuss the managerial implications of each proposition; and finally, we discuss conclusions, limitations and future research directions.

8

\section{Extension of the concept of relational rents to the portfolio level}

The foundational theory upon which our theoretical model is constructed is that of the relational view $(\mathrm{RV})$. This theory states that a relationship can provide a unique source of profit through the jointly created and idiosyncratic elements developed within the context of an inter-organizational relation (Dyer \& Singh, 1998). This type of profit is known as relational rent and is defined as:

"supernormal profit jointly generated in an exchange relationship that cannot be generated by either firm in isolation and can only be created through the joint idiosyncratic contributions of the specific alliance partners" (Dyer \& Singh, 1998, p. 662). 
Knowledge transfer within relationship portfolios: the creation of knowledge recombination rents

In this paper, we adopt an extended concept of relational rent that draws upon the concepts of appropriated relational rents and spillover rents (Lavie, 2006). Appropriated relational rents come from the "real" interaction between two parties, i.e. they are outcomes of the process of sharing resources. In Lavie's vision, they are called appropriated in as much as jointly achieved outcomes can be appropriated depending upon the absorptive capacity, bargain power and opportunism of the parties to the relationship. Spillover rents, also known as knowledge leakages, are rents derived from an unintended effect of levering a resource. Examples of such spillovers include the imitation of technologies, business models or productive layouts and the copying of patented products. Opportunistic behaviour, bargaining power and absorptive capacity have positive influences on the creation of these rents while mechanisms of isolation reduce it (Lavie, 2006).

Our model uses Lavie's (2006) concept of extended relational rent to explore how knowledge is transferred and recombined within the firm's portfolio of inter-organizational relationships, which we conceptualize as the ego-network space that consists of the set of relationships a firm has with other organizations and the recombination of different firms' knowledge patrimonies (e.g., Jin-Hai, Anderson, \& Harrison, 2003; Kogut \& Zander, 1992; LeLoarne \& Maalaoui, 2015). Indeed, we argue that a complete understanding of relational rents can only be achieved with a complex three level model consisting of: internal rents, i.e. the idiosyncratic combination of internal resources and capability belonging to a firm; relational rents, i.e. the appropriated relational rents and spillovers, which are the idiosyncratic synergies achievable in a relationship (Lavie, 2006); and finally, knowledge recombination rents that are achieved at the portfolio level. In the RV literature, the final perspective is underdeveloped (Provan, Fish, \& Sydow, 2007) and will be developed within our model. 
Knowledge transfer within relationship portfolios: the creation of knowledge recombination rents

\section{The three pillars of knowledge recombination rents}

132
Our concept of knowledge recombination rents consists of three pillars, which are presented in Table1 below.

$$
\text { **** Insert Table } 1 \text { about here**** }
$$
definition of knowledge recombination rent is the rent that results from the recombination of multiple knowledges among multiple relationship partners. This represents a departure from the extant literature, which has tended to focus on the recombination of knowledge between two relationship partners (e.g., Lavie, 2006).

The second pillar concerns how these rents are generated. To understand this, we need to differentiate between potential and realized knowledge recombination rents. Potential recombination rents are the range of opportunities that exist to recombine knowledge within a portfolio of inter-organizational relationships. As we premised, our model explains how to evaluate and spot potential knowledge recombination rents that can arise from a specific configuration of a firm's inter-organizational relationships portfolio. Thus, in line with a RV approach (Dyer \& Singh, 1998), we are concerned about individuating specific conditions and configurations of a portfolio.

$$
\text { Realized recombination rents instead are those that the firm is actually able to }
$$
appropriate within the real relationship context. This second step instead is more related to the dynamic capabilities possessed by the firm, such its relational capability and absorption capacity just to name a few of the most important for these matters (Lorenzoni \& Lipparini, 1999; Zollo \& Winter, 2002). However, due to space constrains, this second aspect is not included in the present study. 
Knowledge transfer within relationship portfolios: the creation of knowledge recombination rents

Figure 1 visually summarises the two pillars stressed up to this point. The focal firm in a relationship context gets access to internal, appropriated and spillover rents, which do not depend upon the firm's involvement within a network. The potential to earn knowledge recombination rents starts when the focal firm strategically interprets the possibility to recombine one of its precedent rents with other rents obtained or obtainable in other

161 relationship contexts. In the end, the realization of these potential rents will depend upon the 162 relationship context, the firm's dynamic capabilities, and the interaction between the focal 163 firm and its partner. which knowledge recombination rents at the level of the portfolio can be increased or reduced. The third pillar is the central contribution of our model. We adopt a contingency approach, since different contingencies, either internal or external, experienced by the focal firm require different adjustments and alignments to find a fit within the inter-organizational 171 portfolio (Miles \& Snow, 1994). So, our definition of fit is related to an intentional searched accordance between relevant firm' conditions and the ego-network of relationships possessed

173 in order to boost the performance (Zajac, Kraatz, \& Bresser, 2000). In the specific case, an

174 internal fit is a positive condition of alignment between internal elements of the firm and the

175 portfolio which leads to the creation of what we termed internal knowledge recombination

176 rents. An external fit instead regards a positive condition of alignment between external

177 (relational) elements of the firm and the portfolio which leads to the creation of what we 178 termed external knowledge recombination rents. 
Knowledge transfer within relationship portfolios: the creation of knowledge recombination rents

181 Internal knowledge recombination rents (internal fit)

The first contingencies that we will be presented in our model are those related to

internal fit. There are two types of contingency presented: evolution stage and strategy which need to find alignment with the portfolio, thus a fit.

Evolution stage fit

The first element with which the portfolio should find an alignment and a fit is the evolution stage. We refer to this element as the life stage of a firm in which we may distinguish two phases. The first is related to the "infancy of firm" from its formation to its survival (Davidsson \& Honig, 2003), while the maturity phase can be regarded as the stage in which a firm has been established and created a source of competitive advantage within its industry (Gargiulo \& Benassi, 2000). This stage also includes episodes of crises, decline and rejuvenation (e.g., McKinley, 1993; Stopford \& Baden-Fuller, 1990). entrepreneurial literature. Although new entrepreneurs are often innovators within their industries (Christensen \& Bower, 1996; LeLoarne \& Maalaoui, 2015; Rothaermel, 2001), they encounter significant challenges, such as demonstrating their worth to the industry and striving against competitive pressures within a scarce-resource environment. Hence, the core ability of new entrepreneurs is to successfully attain, at minimum cost, the necessary resources needed to compete while often having to rely only on what is at hand, such as their existing relations and kinships (Hanlon \& Saunders, 2007). structure constituted by a high number of bonding ties with embedded elements of trust,

203 mutual reciprocity and strong emotional commitment that transcend purely rational and 204 economic logics (Chung, Luo, \& Wagner, 2006; Huggins, 2010; Zhao, 2014). When 
Knowledge transfer within relationship portfolios: the creation of knowledge recombination rents

implementing entrepreneurial strategies, these networks will likely obtain better results than networks constituted by relationships based on a more transactional logic, such as relations with new business partners (Hoang \& Antoncic, 2003). This is consistent with the perspective of transaction cost economics in which strong ties are built upon reiterated exchanges with the same partner, who becomes increasingly trustworthy and incurs lower transactions costs as a result (Williamson, 1975).

For new entrepreneurs within an industry, newness is often a liability as much as a benefit but it is a liability that can be offset through establishing a portfolio of collaborative relationships that forms a network of bonding ties (Abatecola, Cafferata, \& Poggesi, 2012). First, the new companies often need to cooperate (chiefly with the incumbents) due to a resource endowment that is not yet completely developed, e.g. in biotechnology industry the young firms are often very research-oriented but may lack commercial experience (Durand, Bruyaka, \& Mangematin, 2008; Hine \& Kapeleris, 2006; Powell et al., 1996). Second, young ventures can exploit collaborations with high-status incumbents to signal to the market their reliability as an enterprise (Stuart, Hoang, \& Hybels, 1999), for example, encouraging venture capitalists to invest (MacMillan, Siegel, \& Narasimha, 1985). Further, working with well-known partners and within a close network will ensure that behaviour that might considered deviant within the industry is censured (Davidsson \& Honig, 2003).

This ability to meet the expectations of the market through relationships with industry incumbents gives the new ventures "legitimacy" (Lacam \& Salvetat, 2017; Zimmerman \& Zeitz, 2002), which requires the new firm to repeatedly abide by the rules and norms of within the industry. This is in line with our extended definition of knowledge recombination rents in which value is created through a series of positive feedback loops between the new firm and industry incumbents (e.g., Batocchio, Ghezzi, \& Rangone, 2016). This is confirmed in many empirical studies. For instance, Yli-Renko et al. (2001) found that young 
Knowledge transfer within relationship portfolios: the creation of knowledge recombination rents

230 knowledge-based firms perform better if they have repeated and intense interactions with

231 industry incumbents. Similarly, Hansen (1995) found that for start-up companies the closure

232 of their ego-network and the frequency of interactions within the network were the most

233 important predictors of growth, especially when these variables are co-present.

234 In conclusion, new entrepreneurs need a portfolio of inter-organizational relationships

235 that forms a relatively closed network of closely-tied actors in order to: receive support,

236 access resources and capabilities, gain legitimacy and protect themselves from opportunism

237 (Hanlon \& Saunders, 2007; Zhao, 2014). This leads us the development of our first

238 propositions:

Proposition 1.a: In a start-up phase, a portfolio structure with a predominance of

bonding ties, which forms a close network structure, will be most favourable to the creation of knowledge recombination rents.

Proposition 1.b: In a start-up phase, a portfolio structure with a predominance of

bridging ties, which forms a sparse network structure, is unfavourable to the creation of knowledge recombination rents.

Contrary instead seems to be the situation after the susses of a firm on the market; to analyse this firm contingency in respect to its portfolio we draw upon the literature on

250 network and structural holes (e.g., Burt, 2000). The incumbents within an industry often

251 struggle to respond to the rapid, and often radical, changes in technology affecting their

252 industries (Christensen \& Bower, 1996). Therefore, establishing relationships with innovative

253 new ventures is a well-established method to respond to the problem of breakthrough

254 technology (Hoang \& Antoncic, 2003). Nevertheless, embarking upon relationships with 
Knowledge transfer within relationship portfolios: the creation of knowledge recombination rents

255 these businesses is not a risk free activity for incumbent firms (Rothaermel, 2001). To

256 manage the risks of working with unknown business partners, incumbents are advised to

257 maintain relationships with a wide range of new ventures and have flexible agreements in

258 place (Williamson, 1991). This portfolio structure would consist of bridging ties and allow

259 the incumbent to reach a broker position within the network, reaping the advantages of

260 accessing from different sources a large amount of knowledge (Burt, 2000; Lacam \&

261 Salvetat, 2017).

There will still be the need for firms to maintain strong ties with strategic partners

however. For this reason, some authors have proposed the construction of a balanced network structure, also called "dual network structure” (Capaldo, 2007; Tiwana, 2008; Zaheer \& Bell, 2005). Such structure consists of a "network core" formed by few and strategic partners with whom the focal firm shares a bonding tie; and a myriad of bridging ties related to a large and unconnected periphery of other partners. A dual network relieves the redundancy of information, thanks to the ability of the focal firms to access a large and unconnected set of loosely-tied partners within the periphery of the network. However, at the same time, it

270 fosters innovation, thanks to having few bonding ties with strategic partners at the core of the 271 network. This leads to the development of our second set of propositions: knowledge recombination rents. 
Knowledge transfer within relationship portfolios: the creation of knowledge recombination rents

Proposition 2.c: In a maturity phase, a portfolio structure with a dual network

structure, is more favourable than a sparse network structure to the creation of knowledge

recombination rents.

Strategy fit

The second contingency that should find a fit with a firm inter-organizational

portfolio concerns the strategic goals of firms participating in the relationships. To do this, we draw upon March’s (1991) Exploitation-Exploration framework (1991). Exploitation strategies aim to refine existing knowledge, competencies, and technologies, in other words the concern the uses of knowledge already possessed while exploration strategies are more experimental. The firm in this case engages in scanning activities and aims to discovering novel knowledge previously not available for the company and opportunities to get access to it. March's (1991) framework is widely applied to alliance and network studies (e.g., Lavie \& Rosenkopf, 2006; Lavikka, Smeds, \& Jaatinen, 2015; Yamakawa, Yang, \& Lin, 2011). complementary resources and knowledge to better use the actual patrimony they already possess (Koza \& Lewin, 1998). In such cases, agreements usually take the form of equity investments, licensing or franchising agreement, and emphasis is on results and control over the process, since at stake there is firm's already consolidated knowledge (Lavie \&

300 Rosenkopf, 2006). In contrast, an exploration relationship is more likely to be used as a 301 means to penetrate new markets, to develop new products and technological opportunities, 302 and usually takes the form of an open-ended agreement, e.g. an R\&D agreement or a learning 303 joint venture. In such agreements, the emphasis is less on results and more on the interaction 304 itself (Yamakawa et al., 2011). Beckman et al. (2004) assert that exploration relationship 
Knowledge transfer within relationship portfolios: the creation of knowledge recombination rents

strategies are executed by enlarging the size of network by creating new social interactions with new partners, while exploitation strategies reinforce existing relationships by reinforcing connections with the same partners (Woolfall, 2006). Most of the authors (e.g. Park, Chen, \&

Gallagher, 2002; Rothaermel \& Deeds, 2004) agreed on the idea that explorative and exploitative strategies can experience a fertile environment in a certain structure of the focal firm's relationships portfolio.

Exploitation strategies will be more effective when supported by a nexus of dense and cohesive relationships (e.g., Dyer \& Nobeoka, 2000; Kogut, 2000), due to the fact that easy mobilisation of resources and tacit knowledge, and cooperation possible through bonding ties seem more proper (Obstfeld, 2005; Reagans \& McEvily, 2003).

In contrast, exploration strategies rely mostly on the creation of new ties with new actors, which allows them to access novel knowledge and possibly the knowledge available through the networks of these actors (Burt, 2004; Podolny and Baron, 1997). The creation of novel ideas in a close-knit structure can be drastically reduced due to isomorphism and standardization of knowledge's flows inside it (Burt, 1992; Gargiulo \& Benassi, 2000), that instead is vital in a not well-defined context along with dynamicity and flexibility (Sidhu, Commandeur, \& Volberda, 2007).

It has been observed that firms can have a "firm-genetic inclination" towards either an exploitation and exploration relationship strategy (Lavie \& Rosenkopf, 2006; Rothaermel \& Deeds, 2004; Yamakawa et al., 2011). This is because exploration and exploitation strategies can enact self-reinforcing loops. Exploration strategies are more uncertain than exploitation strategies and promote continuous and simultaneous investments in similarly explorative projects, partly to hedge the risk of failure in one project. Exploitation strategies, which tend to be more focused on outcomes within a short period, can be more alluring to managers under pressure to produce quick returns, for example due to pressure from shareholders or to 
Knowledge transfer within relationship portfolios: the creation of knowledge recombination rents

330 increase their personal prestige quickly (Gupta, Smith, \& Shalley, 2006). So either

331 knowledge explorative or exploitative claim for more and successive same-type strategies to

332 accelerate the process of obtaining results (Lavie \& Rosenkop, 2006). Therefore we can

333 propose:

334

Proposition 3: Pursuing an exploitation strategy reinforces the creation of knowledge

recombination rents if the firm possesses a close network structure.

Proposition 4: Pursuing an exploration strategy reinforces the creation of knowledge

recombination rents if the firm possesses a sparse network structure.

To conclude, we can detect a possible "combined effect" that evolution stage and

342 strategy can have in respect to the fit with a relationships portfolio. Giving the fact that

343 entrepreneurial young ventures have an advantage relying on bonding affiliations and the

344 creation of a close and dense network is favourable to an exploitation strategy, it is possible

345 to highlight a strong potential for knowledge recombination rents using exploitation strategy

346 in start-up phase to achieve simultaneous meliorations (e.g., Hine \& Kapeleris, 2006;

347 Yamakawa et al., 2011). For an established corporation, instead, the opposite is exactly true:

348 pursuing an exploration strategy is positive from several perspectives (Burt, 1992; Zahra, 349 2010). 
Knowledge transfer within relationship portfolios: the creation of knowledge recombination rents

\section{External Knowledge recombination rents (external fit)}

352 The second group of contingencies presented in our model are those related to external fit, so

353 the alignment that relationships may find with the overall structure of a firm's portfolio.

354 There are two types of contingency presented: past ties fit, so the "legacy" of previous

355 relationships, and actual ties fit. Indeed from a dynamic angle, the formation of new

356 partnerships deals with a structure of social interactions already constituted (actual network)

357 and a history of interactions (past ties) (Ozcan \& Eisenhardt, 2009; Parise \& Casher, 2003).

358 Past ties fit

359 For analysing this fit, we draw upon literature related to the alliances and particularly

360 the value of experience in such interactions (e.g. Gulati, Lavie, \& Singh, 2009). Many

361 studies have argued that experience can improve the performance of inter-organizational

362 relationships (e.g., Heimeriks, Klijn, \& Reuer, 2009; Koza \& Lewin, 1998; Lavie \&

363 Rosenkopf, 2006; Lorenzoni \& Lipparini, 1999) due to the fact that proficiency in dealing

364 with activities of partnerships in general or with specific partners can increase potential 365 benefits.

366 Know-how accrued from precedent partnerships can help improve a firm's

367 relationship management capabilities and establish routines for selecting partners and

368 monitoring the performance of a relationship (Liebeskind, Oliver, Zucker, \& Brewer, 1996).

369 These capabilities are known as "relational capabilities" within the literature (Dyer \& Singh,

370 1998; Lorenzoni \& Lipparini, 1999), i.e. the ability to identify relationship opportunities,

371 manage interactive relationships, and establish relational routines (Gulati et al., 2009). As we

372 premised however, we are not interested in study the actual processes that leads to the

373 appropriation of such potential value that would be a pure dynamic capabilities approach

374 (Zollo \& Winter, 2002); rather we are arguing that the existence of a more developed stock of 
Knowledge transfer within relationship portfolios: the creation of knowledge recombination rents

375

376

relational capabilities (Koza \& Lewin, 2000) offers per se potential value for knowledge recombination and its rents.

In the extant literature, disagreement exists on what exactly should be considered "experience". We can refer to two types of experience capital: the general and the specific ones; both predict that potential rents will decrease as the network of relationships increases in size and stabilising over time (Heimeriks \& Duysters, 2007; Kale \& Singh, 2007; Woolfall, 2006). We will start our discussion with the specific experience that is the set of precedent contacts with the same partner (Wassmer, 2010). While we broadly agree with this conceptualization of experience, there are other kinds of specificity that experience can have beyond the partner interactions. Markedly, we are drawing upon our considerations in the strategy fit section, to propose a strategy of specific experience (Koza \& Lewin, 1998; Lavie \& Rosenkopf, 2006). We have already pointed out how strategies are conservative in nature, since company actions, especially when they are successful, tend to result in the institutionalization of successful routines (Nelson \& Winter, 2009), including relational routines (Parise \& Casher, 2003).

There are two types specific experience: exploitation experience and exploration experience. Exploitation experience is created by routines that are established to improve the implementation of actions, while exploration experience consists of recombining novel knowledge (Finkelstein, 2009). In this case, not all of experiences can affect both future strategies outcomes (Heimeriks et al., 2009). What we propose is near to the concept of "diversity of ties" but applies to the context of past relationships, that is directing attention on "cluster" of relations similar for attributes of partners firms or knowledge to manage (Jiang et al., 2010; Lavie \& Rosenkopf, 2006; Ozcan \& Eisenhardt, 2009; Phelps, 2010). For every new social interaction settled by a corporation concordant in type with the previous ones, management can structure, collaborate, and control the new relationship in the 
Knowledge transfer within relationship portfolios: the creation of knowledge recombination rents

400

401

best way they know. In the case of a non-concordant strategy, it can exist an "organizational inertia" (Lavie \& Rosenkopf, 2006) since for the management is easier to continue applying company's consolidated routines. But this does not consider important divergent learning paths and interaction diversity, which can sharply diminish potential outcomes of a relationship. For example, exploitation is based on short-term results and its control is resultoriented, while in exploration strategy, with its uncertainty, the control is process-oriented (Gupta et al., 2006; Koza \& Lewin, 1998; Rothaermel, 2001; Yamakawa et al., 2011). That implies a completely different contract structuring and forma mentis approach to strategy. Applying a mistaken repertory of routines, inevitably fosters the failure of a relationship. It seems plausible that such specific experience has a direct influence on potential relationship gains due to a specialization of routines directly applicable to a strategy context, or at least they can be given as rules for structuring and governing the relationship process. Thus, we postulate: rents if a firm possesses a concordant specific experience.

Proposition 5a: A relationship increases the creation of knowledge recombination

Proposition 5b: A relationship hinders the creation of knowledge recombination rents if a firm possesses a non-concordant specific experience.

Considering instead, general experience this can be related to every previous firms' interactions (Gulati et al., 2009), and as pointed out by successive works of Kale and Singh (2007, 2009) and Heimeriks and colleagues (2007; 2009) this type of experience supports the success of a relationship only in an indirect way. This also appraises general experience as less relevant in performance outcomes compared the specific one (Wassmer, 2010). General 
Knowledge transfer within relationship portfolios: the creation of knowledge recombination rents

experience so is helpful only when consents a better relationship process and learning thanks to the codification and sharing of explicit knowledge (Holmberg \& Cummings, 2009). To facilitate such transfer of best practices, management should be forced to dedicate attention to the such problem (Kale \& Singh, 2007; Parise \& Casher, 2003), having managerial roles specifically dedicated to partnerships, such as an alliance manager or in some cases even a dedicated function. Therefore, we propose:

recombination rents if the firm possesses formal structure and/or routines dedicated to the relationship process.

\section{Actual ties fit}

A crucial aspect of knowledge recombination rents creation in the same portfolio is the possibility to share resources among several relationships. Vassolo et al. (2004), for instance, accredited that a portfolio which is full of competing projects has a sub-additive effects on each one. This is closely coupled to the concepts of real options where the firm must choose between incompatible projects. In contrast, shared resources across relationships has the potential to create economies of scope and can have a super-additive effect upon a firm's portfolio of inter-organizational relationships.

Lavie (2009) considers the effect of having competing relationship partners in a firm's portfolio, also known as coopetition (Le Roy \& Czakon, 2016). If a direct (bilateral) coopetition can weaken the results of a relationship, the competition among partners (multilateral coopetition) can strengthen the power of the focal firm which is in a position to gain more potential profits. For example, empirical insights from a recent review on coopetition (Le Roy \& Czakon, 2016) shows how in network environments cooperation with 
Knowledge transfer within relationship portfolios: the creation of knowledge recombination rents

competitors led to better performance. Nevertheless, the problem of competing partners is controversial; whereas for a venture can be advantageous have competing firms in its portfolio if this process is not coupled with a strong process of communication and trust, partners can decide to interrupt their relations (White \& Siu - Yun Lui, 2005). However, this last concern is more based on the process of appropriation of rents, that is beyond the scope of our paper. To conclude our model, we present the following propositions:

Proposition 7a: A new tie, despite its nature, can ameliorate the creation of knowledge recombination rents if it relies upon shared resources with other ties. recombination rents if it relies upon competing resources with other ties.

Proposition 7b: A new tie, despite its nature, can reduce the creation of knowledge 4 sis

(n)

**** Insert table 2 about here**** \\ In table 2, a summary of the whole set of propositions we
\[ * * * * \text { Insert table } 2 \text { about here**** } \]}


Knowledge transfer within relationship portfolios: the creation of knowledge recombination rents

475 (proposition 1.a). Due to a lack of well-developed internal capital, especially in terms of

476 human and financial capital, instead it is not recommendable to interact and partner only with

477 arm-length partners or on a sporadic basis since the cost of controlling the relation would be

478 too high (White \& Siu-Yun Lui, 2005; Williamson, 1975) (proposition 1.b).

For an established business, instead, the situation is almost the reverse. Partnering

only with well-known counterparts, may trap the firm in its own strategic space (Uzzi, 1997;

481 Wassmer, 2010), reducing the possibility to renovate social capital and to span the traditional competition territories (proposition 2.a). This approach may indeed pose the firm in a strong defensive position rather than be proactive and catch or even promote market changes, that can be better addressed by continuously exploring new partnerships (Rothaermel, 2001) (proposition 2.b). However, as proposed, a balance view seems to be the best solution: a bundle of partners who can really sustain the implementation of any strategic action (Batocchio et al., 2016), coupled with a larger in number "periphery" represented by new relationships to sound the competitive arena and track new innovation leads (Capaldo, 2007; Tiwana, 2008) (proposition 2.c). Thus, for relationship managers of established companies, the suggestion is to carefully map the whole set of firm's relations to evaluate those more 491 strategic to be kept stable, while continuously engaging with new explorative collaborations 492 (Lavikka et al., 2015). resources to partner with trustful and well-known partners when the firm's strategy is devoted to exploit and consolidate positions and rip benefits of an innovation for example (Ozcan \&

496 Eisenhardt, 2009). In this case, strong relations will definitely help in implementing and 497 executing such actions (Batocchio et al., 2016) since the adaption capability in the knowledge transfer will be higher (Williams, 2007) with minor coordination costs (White \& Siu-Yun Lui, 2005; Williamson, 1991) (proposition 3). Contrary, due to the intrinsic uncertainty of an 
Knowledge transfer within relationship portfolios: the creation of knowledge recombination rents

500 important to the survival and success of firms, especially those firms whose competitive

exploratory project, the firm and its relationship managers should engage with a plurality of subjects that gradually will be evaluated and in case replaced (White \& Siu-Yun Lui, 2005) if not of a transversal utility among different knowledge platform (Lavikka et al., 2015) (proposition 4).

Looking at the experiences of firms in dealing with alliances and collaborative relationships, we have pointed out how a specific strategy experience in partnering may improve the ability to recombine the knowledge coming from that type of interaction (proposition 5.a) thanks a better adaption (Williams, 2007). However, this effect may also create a path dependency (Koka \& Prescott, 2008; Zollo \& Winter, 2002), which may lead to reiterate an erroneous adaption to of knowledge transfer in case of changing strategy (proposition 5.b). To moderate this clashing effects, we encourage any firms to establish formal structures that could keep track of repertory routine so that the tacit knowledge derivate from the experience may be replicate in an easier manner (Ozcan \& Eisenhardt, 2009; Williams, 2007) (proposition 6).

Finally, in terms of sharing of resources among different relationships, relying on the possibility of replication of routines and with non-exclusive resources (Williamson, 1991) may increase the potential creation of network value (proposition 7.a). Instead for the opposite condition, i.e. locking-in resources to specific relationships may reduce the ability to leverage them on different projects (Le Roy \& Czakon, 2016), and the relative synergic value arising (proposition 7.b).

$$
\text { important to the survival and suceess of firms, especially those firms whose competitive }
$$
advantage depends upon innovation (e.g., Chung et al., 2006). Few contributions have 
Knowledge transfer within relationship portfolios: the creation of knowledge recombination rents

approached in a comprehensive way the problem of potential transfers of knowledge within a portfolio of relationships. The prevalent literature deals with partnerships individually in a dyadic perspective even if multiple relations co-exist and thus analyses of this type completely disregard potential interactions that multiple ties could have (Lavie, 2009). Our work aims to confer a theoretical orienting compass, in the tradition of RV, which propose to a fit (Zajac, Kraatz, \& Bresser, 2000) a contingent variable, either internal or external, in relation to a firm's relationships portfolio. Contributing to a growing field of research (e.g., Zhao, 2014), we presented a holistic framework on the network rents, especially dedicated to the simultaneous management of more than one tie.

Our main contributions to the literature are basically two: first, we clearly defined the concept of knowledge recombination rents applied to a firm's inter-organizational portfolio; and, second, we inquired which contingencies may hinder or propel the creation of such rents. Our concept goes beyond the dyadic relational rents since refers to network rents specifically the ones arising from the recombination of knowledge within a firm's egonetwork. This affirms again that the value of a knowledge transfer is not always and only determined by the exchange itself. Rather, such value can be increased after the exchange thanks to a recombination with other "pieces" of knowledge obtainable from the firm's network, so related to other business relationships (Woolfall, 2006).

Regarding our second contribution, a first category of conditions, evolution stage and contents of strategy, relates to the internal situation of the firm and how this should be aligned with the portfolio structure for boosting recombination of knowledge in the network space (internal knowledge recombination rents). The second category of conditions considers the portfolio itself. The knowledge transfer can be increased in state of consonance of the overall portfolio (actual ties fit) and/or of previous experience (past ties fits) (external knowledge recombination rents). 
Knowledge transfer within relationship portfolios: the creation of knowledge recombination rents

The value of our model is to have put together, in a same framework, all the vital

551 attributes to look at, beyond the partnerships dyadic level. Such theoretical contributions

552 combined represent also strong managerial implications of this work; first our work indicates

553 an additional crucial area of attention for relationship managers as much as any other

554 manager involved in external partnerships, such as a R\&D director, an alliance manager, a

555 supply chain manger, and not least the whole general direction. Such managers should pay

556 equally attention to the dyadic level of the relation (Dyer \& Singh, 1998; Lavie, 2006), which

557 represents the actual value of the relation and of the knowledge transfer, but also to the value

558 that such knowledge can acquire after the exchange, thanks indeed to a recombination. While

559 traditional practitioner-oriented literature about alliance managers (e.g., Lynch, 1993;

560 Spekman, Isabella, \& MacAvoy, 2000) considers mostly the first aspect, in recent evolutions

561 (e.g., Zoogah \& Peng, 2011) a general emphasis on the adaptive capacity of such a manager

562 to design a coherent portfolio is much more prominent and we echo such claims. Yet, we

563 offered a quite detail and practical tool formed by 7 propositions that should be checked

564 before engaging with a new relationship as detailed reported in the managerial implication

565 section. The possibility of evaluating ex-ante, not only the value of the relationship but also

566 its potential to increase firm performance after the interaction, is a powerful tool at

567 disposition of alliance managers or any other manager deputy to the management of external

568 relationships.

569 We see particularly two contexts where our model and its application could be

570 crucial: the first is in relation to a firm with an incumbent position (Christensen \& Bower,

571 1996), that it is not favourable to radically innovate. Thus, the primary task of a relationship

572 manager is structuring a relationship portfolio that can sustain innovation and delivering

573 externally the strategic renewal not achievable internally (e.g., Liebeskind et al., 1996;

574 Rothaermel, 2001). However, in doing so the consideration of the specific past experience 
Knowledge transfer within relationship portfolios: the creation of knowledge recombination rents

575 should be taken into account, as we shown in our proposition 3 and 4 . Yet, a manager should

576 try to continuously renovate the geometry of its relationship portfolio, as shown in

577 proposition $2(. a, . b, . c)$.

578 The ability of a manager to control in advance the impacts of a new collaboration

579 results similarly crucial in situations of strong ambiguity, for example where to clearly assess

580 the effects of a relationship the time span is quite long. Examples of this could be referred to

581 the biotechnology sector where a trial conclusion and the related approval from the public

582 agency (e.g. Food and Drug Agency (FDA) in U.S.) may take years, usually more than ten; a

583 period long enough to seriously compromise the ability company to survive if a wrong

584 relationship is started. The possibility of having an ex-ante detailed evaluation of the fit of a

585 new collaboration with the regards of the overall portfolio structure, can reduce the risk of

586 uncertainty and the negative effects.

Further research in relation to our study can be moved in two directions: an interpretation of the appropriation scheme for the knowledge recombination rents, moving from a potential to a concrete level of incremented firm performance. Also, an empirical validation of our proposition must be done to strengthen our results. One good applicative 591 example is represented by the whole technology- and knowledge-intense sector such as the 592 biotechnology and pharmaceutics, internet of things (IoT) and the 2.0 web (e.g., Caputo, 593 Marzi, \& Pellegrini, 2016; Trequattrini, Shams, Lardo, \& Lombardi, 2016). Moreover, future 594 research could investigate the impact of knowledge recombination rents in the different 595 phases of a maturity stage of firm, particularly, it would be interesting to understand how 596 they would impact phases of crisis, decline and rejuvenation (e.g., McKinley, 1993; Stopford 597 \& Baden-Fuller, 1990).

A limitation of our study is the broad generalization that we made in our propositions, 
Knowledge transfer within relationship portfolios: the creation of knowledge recombination rents

600 internal and external fits. These considerations are rooted in the general environments, like a

601 balancing effect in the relationship portfolio pertinent to the geographic localization of the

602 firm (the cluster or district effect) (Lacam \& Salvetat, 2017) or the structural situation of the

603 industry which can widely change the general proactive orientation of those engaging in

604 partnerships.

605

606 
Knowledge transfer within relationship portfolios: the creation of knowledge recombination rents

607

608

609

610

611

612

613

614

615

616

618

619

620

621

622

\section{References}

Abatecola, G., Cafferata, R., \& Poggesi, S. (2012). Arthur Stinchcombe's "liability of newness": contribution and impact of the construct. Journal of Management History, $18(4), 402-418$.

Batocchio, A., Ghezzi, A., \& Rangone, A. (2016). A method for evaluating business models implementation process. Business Process Management Journal, 22(4), 712-735.

Burt, R. S. (1992). Structural Holes: The Social Structure of Competition. Boston, MA: Harvard University Press.

Burt, R. S. (2000). The network structure of social capital. Research in Organizational Behavior, 22, 345-423.

Capaldo, A. (2007). Networking structure and innovation: The leveraging of a dual network as a distinctive relational capability. Strategic Management Journal, 28(6), 585-608.

Caputo, A., Marzi, G., \& Pellegrini, M.M. (2016). The Internet of Things in Manufacturing Innovation Processes: Development and Application of a Conceptual Framework, Business Process Management Journal, 22(2), 383-402.

Christensen, C. M., \& Bower, J. L. (1996). Customer power, strategic investment, and the failure of leading firms. Strategic Management Journal, 197-218.

Chung, Q. B., Luo, W., \& Wagner, W. P. (2006). Strategic alliance of small firms in knowledge industries: A management consulting perspective. Business Process Management Journal, 12(2), 206-233.

Davidsson, P., \& Honig, B. (2003). The role of social and human capital among nascent entrepreneurs. Journal of Business Venturing, 18(3), 301-331.

Durand, R., Bruyaka, O., \& Mangematin, V. (2008). Do science and money go together? The case of the French biotech industry. Strategic Management Journal, 29(12), 1281-1299.

Dyer, J. H., \& Nobeoka, K. (2000). Creating and managing a high-performance knowledge- 
Knowledge transfer within relationship portfolios: the creation of knowledge recombination rents

632

633

634

635

636

637

638

639

640

641

642

643

644

645

646

647

648

sharing network: the Toyota case. Strategic Management Journal, 345-367.

Dyer, J. H., \& Singh, H. (1998). The relational view: Cooperative strategy and sources of interorganizational competitive advantage. Academy of Management Review, 23(4),

$$
660-679 .
$$

Finkelstein, S. (2009). The effects of strategic and market complementarity on acquisition performance: Evidence from the US commercial banking industry, 1989-2001. Strategic Management Journal, 30(6), 617-646.

Gargiulo, M., \& Benassi, M. (2000). Trapped in your own net? Network cohesion, structural holes, and the adaptation of social capital. Organization Science, 11(2), 183-196.

Gulati, R. (1998). Alliances and Networks. Strategic Management Journal, 19(4), 292-317.

Gulati, R., Lavie, D., \& Singh, H. (2009). The nature of partnering experience and the gains from alliances. Strategic Management Journal, 30(11), 1213-1233.

Gupta, A. K., Smith, K. G., \& Shalley, C. E. (2006). The interplay between exploration and exploitation. Academy of Management Journal, 49(4), 693-706.

Hanlon, D., \& Saunders, C. (2007). Marshaling Resources to Form Small New Ventures: Toward a More Holistic Understanding of Entrepreneurial Support. Entrepreneurship Theory and Practice, 31(4), 619-641.

Hansen, E. L. (1995). Entrepreneurial networks and new organization growth. Entrepreneurship: Theory and Practice, 19(4), 7-20.

Heimeriks, K. H., \& Duysters, G. (2007). Alliance capability as a mediator between experience and alliance performance: An empirical investigation into the alliance capability development process. Journal of Management Studies, 44(1), 25-49.

Heimeriks, K. H., Klijn, E., \& Reuer, J. J. (2009). Building capabilities for alliance portfolios. Long Range Planning, 42(1), 96-114.

Hine, D., \& Kapeleris, J. (2006). Innovation and entrepreneurship in biotechnology, an 
Knowledge transfer within relationship portfolios: the creation of knowledge recombination rents international perspective: Concepts, theories and cases. Edward Elgar Publishing.

Hoang, H., \& Antoncic, B. (2003). Network-based research in entrepreneurship: A critical review. Journal of Business Venturing, 18(2), 165-187.

Holmberg, S. R., \& Cummings, J. L. (2009). Building successful strategic alliances: strategic process and analytical tool for selecting partner industries and firms. Long Range Planning, 42(2), 164-193.

Huggins, R. (2010). Forms of Network Resource: Knowledge Access and the Role of InterFirm Networks. International Journal of Management Reviews, 12(3), 335-352.

Jiang, R. J., Tao, Q. T., \& Santoro, M. D. (2010). Alliance portfolio diversity and firm performance. Strategic Management Journal, 31(10), 1136-1144.

Jin-Hai, L., Anderson, A. R., \& Harrison, R. T. (2003). The evolution of agile manufacturing. Business Process Management Journal, 9(2), 170-189.

Kale, P., \& Singh, H. (2007). Building firm capabilities through learning: the role of the alliance learning process in alliance capability and firm-level alliance success. Strategic Management Journal, 28(10), 981-1000.

Kale, P., \& Singh, H. (2009). Managing strategic alliances: what do we know now, and where do we go from here? The Academy of Management Perspectives, 45-62.

Kogut, B. (2000). The network as knowledge: Generative rules and the emergence of structure. Strategic Management Journal, 405-425.

Kogut, B., \& Zander, U. (1992). Knowledge of the firm, combinative capabilities, and the replication of technology. Organization Science, 3(3), 383-397.

Koka, B. R., \& Prescott, J. E. (2008). Designing Alliance Networks: The Influence Of Network Position, Environmental Change, And Strategy On Firm Performance. Strategic Management Journal, 29(6), 639-661.

Koza, M. P., \& Lewin, A. Y. (1998). The co-evolution of strategic alliances. Organization 
Knowledge transfer within relationship portfolios: the creation of knowledge recombination rents

682

683

684

685

686

687

688

689

690

691

692

693

694

695

696

697

698

699

700

701

702

703

704

705

706

Science, 9(3), 255-264.

Lacam, J. S., \& Salvetat, D. (2017). The complexity of co-opetitive networks. Business Process Management Journal, 23(1), 176-195.

Lavie, D. (2006). The competitive advantage of interconnected firms: An extension of the resource-based view. Academy of Management Review, 31(3), 638-658.

Lavie, D. (2009). Capturing value from alliance portfolios. Organizational Dynamics, 38(1), 26-36.

Lavie, D., \& Rosenkopf, L. (2006). Balancing exploration and exploitation in alliance formation. Academy of Management Journal, 49(4), 797-818.

Lavikka, R., Smeds, R., \& Jaatinen, M. (2015). A process for building inter-organizational contextual ambidexterity. Business Process Management Journal, 21(5), 1140-1161.

Le Roy, F., \& Czakon, W. (2016). Managing coopetition: the missing link between strategy and performance. Industrial Marketing Management, 53, 3-6.

LeLoarne, S., \& Maalaoui, A. (2015). How high-tech entrepreneurs bricole the evolution of business process management for their activities. Business Process Management Journal, 21(1), 152-171.

Liebeskind, J. P., Oliver, A. L., Zucker, L., \& Brewer, M. (1996). Social networks, learning, and flexibility: Sourcing scientific knowledge in new biotechnology firms. Organization Science, 7(4), 428-443.

Lorenzoni, G., \& Lipparini, A. (1999). The leveraging of interfirm relationships as a distinctive organizational capability: a longitudinal study. Strategic Management Journal, 317-338.

Lynch, R. P. (1993). Business alliances guide: The hidden competitive weapon. Wiley. MacMillan, I. C., Siegel, R., \& Narasimha, P. N. S. (1985). Criteria used by venture capitalists to evaluate new venture proposals. Journal of Business Venturing, 1(1), 119- 
Knowledge transfer within relationship portfolios: the creation of knowledge recombination rents 128.

March, J. G. (1991). Exploration and exploitation in organizational learning. Organization Science, 2(1), 71-87.

McKinley, W. (1993). Organizational decline and adaptation: Theoretical controversies. Organization Science, 4(1), 1-9.

Nelson, R. R., \& Winter, S. G. (2009). An evolutionary theory of economic change. harvard university press.

Obstfeld, D. (2005). Social networks, the tertius iungens orientation, and involvement in innovation. Administrative Science Quarterly, 50(1), 100-130.

Ozcan, P., \& Eisenhardt, K. M. (2009). Origin of alliance portfolios: Entrepreneurs, network strategies, and firm performance. Academy of Management Journal, 52(2), 246-279.

Parise, S., \& Casher, A. (2003). Alliance portfolios: Designing and managing your network of business-partner relationships. The Academy of Management Executive, 17(4), 25-39.

Pett, T. L., \& Clay Dibrell, C. (2001). A process model of global strategic alliance formation.

Phelps, C. C. (2010). A longitudinal study of the influence of alliance network structure and composition on firm exploratory innovation. Academy of Management Journal, 53(4), 890-913.

Podolny, J. M., \& Baron, J. N. (1997). Resources and relationships: Social networks and

Powell, W. W., Koput, K. W., \& Smith-Doerr, L. (1996). Interorganizational Collaboration and the Locus of Innovation: Networks of Learning in Biotechnology. Administrative Science Quarterly, 41(1), 116-145.

Pratono, A. H. (2016). Strategic orientation and information technological turbulence: 
Knowledge transfer within relationship portfolios: the creation of knowledge recombination rents 382.

Provan, K. G., Fish, A., \& Sydow, J. (2007). Interorganizational networks at the network level: A review of the empirical literature on whole networks. Journal of Management, $33(3), 479-516$.

Reagans, R., \& McEvily, B. (2003). Network structure and knowledge transfer: The effects of cohesion and range. Administrative Science Quarterly, 48(2), 240-267.

Rothaermel, F. T. (2001). Incumbent's advantage through exploiting complementary assets via interfirm cooperation. Strategic Management Journal, 22(6-7), 687-699.

Rothaermel, F. T., \& Deeds, D. L. (2004). Exploration and exploitation alliances in biotechnology: A system of new product development. Strategic Management Journal, 25(3), 201-221.

Sidhu, J. S., Commandeur, H. R., \& Volberda, H. W. (2007). The multifaceted nature of exploration and exploitation: Value of supply, demand, and spatial search for innovation. Organization Science, 18(1), 20-38.

Spekman, R. E., Isabella, L. A., \& MacAvoy, T. C. (2000). Alliance competence: Maximizing the value of your partnerships. John Wiley \& Sons.

Stopford, J. M., \& Baden-Fuller, C. (1990). Corporate rejuvenation. Journal of Management Studies, 27(4), 399-415.

Stuart, T. E., Hoang, H., \& Hybels, R. C. (1999). Interorganizational endorsements and the performance of entrepreneurial ventures. Administrative Science Quarterly, 44(2), 315349.

Tiwana, A. (2008). Do Bridging Ties Complement Strong Ties? An Empirical Examination Of Alliance Ambidexterity. Strategic Management Journal, 29(3), 251-272.

Trequattrini, R., Shams, R., Lardo, A., \& Lombardi, R. (2016). Risk of an epidemic impact when adopting the Internet of Things: The role of sector-based resistance. Business 
Knowledge transfer within relationship portfolios: the creation of knowledge recombination rents

Process Management Journal, 22(2), 403-419.

Uzzi, B. (1997). Social structure and competition in interfirm networks: The paradox of embeddedness. Administrative Science Quarterly, 42(1), 35-67.

Vassolo, R. S., Anand, J., \& Folta, T. B. (2004). Non-additivity in portfolios of exploration activities: A real options-based analysis of equity alliances in biotechnology. Strategic Management Journal, 25(11), 1045-1061.

Wassmer, U. (2010). Alliance portfolios: A review and research agenda. Journal of Management, 36(1), 141-171.

White, S., \& Siu-Yun Lui, S. (2005). Distinguishing costs of cooperation and control in alliances. Strategic Management Journal, 26(10), 913-932.

Williams, C. (2007). Transfer in context: Replication and adaptation in knowledge transfer relationships. Strategic Management Journal, 28(9), 867-889.

Williamson, O. E. (1975). 1975 Markets and hierarchies New York: Free Press.

Williamson, O. E. (1991). Comparative economic organization: The analysis of discrete structural alternatives. Administrative Science Quarterly, 269-296.

Woolfall, D. (2006). A game and network perspective on m-business partnerships. Business Process Management Journal, 12(3), 265-280.

Yamakawa, Y., Yang, H., \& Lin, Z. J. (2011). Exploration versus exploitation in alliance portfolio: Performance implications of organizational, strategic, and environmental fit. Research Policy, 40(2), 287-296.

Yang, H., Lin, Z. J., \& Lin, Y. L. (2010). A multilevel framework of firm boundaries: firm characteristics, dyadic differences, and network attributes. Strategic Management Journal, 31(3), 237-261.

Yli-Renko, H., Autio, E., \& Sapienza, H. J. (2001). Social capital, knowledge acquisition, and knowledge exploitation in young technology-based firms. Strategic Management 
Knowledge transfer within relationship portfolios: the creation of knowledge recombination rents

Zaheer, A., \& Bell, G. G. (2005). Benefiting from network position: firm capabilities, structural holes, and performance. Strategic Management Journal, 26(9), 809-825. https://doi.org/10.1002/smj.482

Zahra, S. A. (2010). Harvesting family firms' organizational social capital: A relational perspective. Journal of Management Studies, 47(2), 345-366.

Zajac, E. J., Kraatz, M. S., \& Bresser, R. K. F. (2000). Modeling the dynamics of strategic fit: A normative approach to strategic change. Strategic Management Journal, 429-453.

Zhao, F. (2014). A holistic and integrated approach to theorizing strategic alliances of small and medium-sized enterprises. Business Process Management Journal, 20(6), 887-905.

Zimmerman, M. A., \& Zeitz, J. G. (2002). Beyond Survival: Achieving New Venture Growth by Building Legitimacy. Academy of Management Review, 27(3), 414-431.

Zollo, M., \& Winter, S. G. (2002). Deliberate learning and the evolution of dynamic capabilities. Organization Science, 13(3), 339-351.

Zoogah, D. B., \& Peng, M. W. (2011). What determines the performance of strategic alliance 508. 

recombination rents

$801 \quad$ List of Tables

Table 1. The "three pillars" of the knowledge recombination rents

\begin{tabular}{ll}
\hline What? & $\begin{array}{l}\text { Recombination of knowledge obtained or spilled from a partner with the ones obtained or spilled from } \\
\text { one or more partners }\end{array}$ \\
\hline How? & $\begin{array}{l}\text { The range of opportunities to recombine derives from the network (Potential knowledge recombination } \\
\text { rents), but real recombination happens only into an alliance context with a specific partner (Realized } \\
\text { knowledge recombination rents) }\end{array}$ \\
\hline When? & $\begin{array}{l}\text { To facilitate the process of creation of potential rents, the network should assume specific } \\
\text { configurations in accord with endogenous firm conditions (internal fit) and exogenous contingences of } \\
\text { the network itself (external fit). }\end{array}$ \\
\hline
\end{tabular}

\section{Internal fit}

Proposition 1.a: In a start-up phase, a portfolio structure with a predominance of bonding ties, which forms a close network structure, will be most favourable to the creation of knowledge recombination rents.

Proposition 1.b: In a start-up phase, a portfolio structure with a predominance of bridging ties, which forms a sparse network structure, is unfavourable to the creation of knowledge recombination rents.

Proposition 2.a: In a maturity phase, a portfolio structure with a predominance of bonding ties, which forms a close network structure, is favourable to the creation of knowledge recombination rents.

Proposition 2.b: In a maturity phase, a portfolio structure with a predominance of bridging ties, which forms a sparse network structure, is favourable to the creation of knowledge recombination rents.

Proposition 2.c: In a maturity phase, a portfolio structure with a dual network structure, is more favourable than a sparse network structure to the creation of knowledge recombination rents.

Proposition 3: Pursuing an exploitation strategy reinforces the creation of knowledge recombination rents if the firm possesses a close network structure.

Proposition 4: Pursuing an exploration strategy reinforces the creation of knowledge recombination rents if the firm possesses a sparse network structure.

\section{External fit}

Proposition 5a: A relationship increases the creation of knowledge recombination rents if a firm possesses a concordant specific experience.

Proposition 5b: A relationship hinders the creation of knowledge recombination rents if a firm possesses a nonconcordant specific experience.

Proposition 6: A new tie despite its nature can increase the creation of knowledge recombination rents if the firm possesses formal structure and/or routines dedicated to the relationship process.

Proposition 7a: A new tie, despite its nature, can ameliorate the creation of knowledge recombination rents if it relies upon shared resources with other ties. 
Knowledge transfer within relationship portfolios: the creation of knowledge recombination rents

Proposition 7b: A new tie, despite its nature, can reduce the creation of knowledge recombination rents if it relies upon competing resources with other ties.

807

808

809

$810 \quad$ List of Figures

811 Figure 1. Knowledge recombination rents: a visual representation

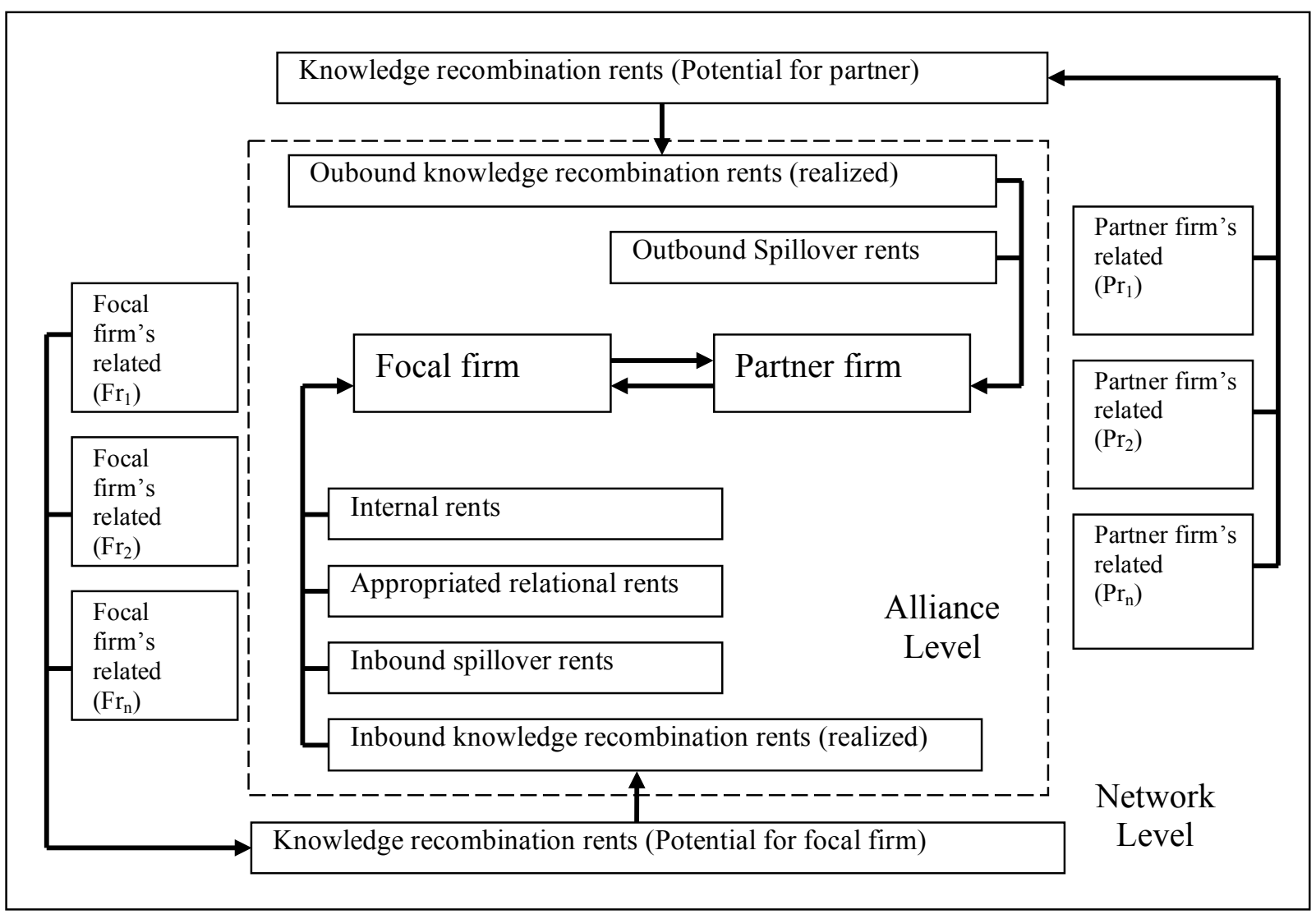

812 